\title{
Playboy's digital journey: Extending the power of the brand
}

\section{Michael Hires}

with over a decade of media experience, directs Playboy's corporate-wide initiative to digitize and catalogue an on-demand library of all its assets. Known as the Playboy Asset Management (PAM) system, the goal of this project is to maximize the asset profitability of one of the world's best-known brands across all media and markets. Hires began his career at Playboy in 1997 and has since served in a variety of roles. Prior to his leadership role with PAM he served as the principal account manager for Playboy's online and wireless licensees.

Keywords: DAM, integrated system, repurposing assets, archives, electronic workflow

Abstract Playboy has launched a corporate wide digital asset management (DAM) solution to leverage assets across media platforms. As that DAM solution gets rolled out across business units the ultimate goal is to have a single repository tied to rights and content management, streamlining the production of new branded content distribution points that are scalable allowing for optimal revenue growth. Journal of Digital Asset Management (2006) 2, 178-180. doi:10.1057/palgrave.dam.3650030

\section{PAM: MANAGING ASSETS, MAXIMIZING PROFITABILITY}

Playboy has a corporate wide initiative to digitize an on-demand library of all its assets. Known as the Playboy Asset Management (PAM) system, the goal of this project is to maximize the asset profitability of one of the world's best-known brands across all media and markets.

\section{INTRODUCTION}

With its rich history of content production, Playboy archives span 53 years of print publishing, 24 years of TV and movie making, 11 years of online publishing, 5 years of radio programming, and 3 years of publishing in the mobile space. Today, there are few media platforms where Playboy can not be found.

Playboy has always been in the forefront of emerging technologies launching one of the first pay cable TV networks and later becoming one of the first national magazines to have an online presence. Our continued search for new

Michael Hires Director,

Digital Asset Management and Distribution, Playboy Enterprises Inc. Tel: (312) 373-2812 E-mail: mhires@playboy.com opportunities to leverage assets initiated its international mobile launch of still images and video in 2003. The legacy of these media is a library that includes millions of photos, as well as cartoons, artwork, video and a range of editorial features.
With every new technology, Playboy remains committed to providing the entertainment people have come to expect from one of the most recognized brands in the world. New technologies create questions around content selection, availability, formats, size, delivery mechanisms, etc. Digital asset management (DAM) is a central part of how we answer these questions and bring content to market.

DAM has been happening in informal ways for decades with everything from departmental access-databases to simple excel-spreadsheets. The role of the PAM system is to build on these informal processes and to streamline them to allow our content creative teams to remain technologically agnostic in a multi-platform world.

Understanding the role of PAM within the existing operational infra-structure required the development of strategies to incorporate new workflows and business rules into the legacy systems. The PAM tag line: "Managing Assets, Maximizing Profitability" was created to inspire corporate wide thinking about how to simplify the reuse of assets in ways that made the best use of the resources at hand. The challenge for PAM is two-fold: to mine existing archives and to leverage our content production to keep pace with changing times and technologies while not slowing down the creation of any end product. PAM is a central component of integrated systems including Rights and Content 
Management. They have been designed to speed product to market with the flexibility of adding new end platforms as they become available.

The PAM system is at the core of who we are and what we do from a content production perspective. It is intertwined and enmeshed in every business production process in every division. It enables us to quickly leverage new business opportunities and distribution channels of our content as they arise.

Mark Laudenslager, Chief Information Officer, Playboy Enterprises

\section{STILL IMAGE ASSETS}

The life of our still image assets begins with the magazine. Our photo editors and art directors conceptualize the ideas and settings for each pictorial situation whether a stand-alone pictorial or as images to illustrate an article. Utilizing a blend of staff and free lance photography talent, the images are executed to extremely high-quality standards in terms of both content and technical quality.

So what happens to a set of images from a photo shoot over the course of its lifetime? For a typical pictorial, only 10-15 of hundreds, sometimes thousands of images taken in the course of a photo shoot will be published in the magazine. Selecting the best images is a process that Playboy photo editors have honed into an art form. Identifying the images that best reflect the purpose and vision of the pictorial or article being illustrated is not an easy task. The challenge of viewing hundreds of film images has only been compounded with the introduction of digital photography.

Advances in the quality of digital photography have enabled Playboy to contemplate the transition from film to digital. However, having a system to edit and archive large numbers of digital images is an absolutely necessary part of the process. And it has to be a system that respects the quality criteria that the magazine has set for itself over the years. Gary Cole, Photography Director, Playboy Magazine

Once selected, the images are turned over to Playboy's Art Department where they are sized and paced for optimum visual effect. The approval process travels through the art director and editorial director of the magazine and, finally, to Editor-in-Chief, Hugh Hefner. Invariably, changes are requested, requiring that more images be identified from the overall edit.

For some companies, the 10-15 images that make the print edition could be the end of the story, leaving the remaining hundreds of pictures sitting in a photo library, never to see the light of day again. Among Playboy's unique qualities is our belief that every asset has value and no asset featuring the brand at Playboy is ever truly retired.

Playboy has always looked for ways of extending the power of the brand of Playboy beyond the core business of our domestic magazine. Our licensed international editions gave us one of the earliest tests of repurposing images and whole layouts came with the launch of the first two non-English editions, Playboy Germany and Playboy Japan. The process worked - today there are 20 editions of Playboy around the world including, Brazil, France, Mexico, the Netherlands, Poland and Russia. Over the years the optimal balance of 80 per cent local content - filled in by 20 per cent US created content, or a combination of content from other foreign editions - has created and extended the global presence of Playboy while adding another source of original material that can be leveraged across other editions or in new technologies.

Playboy works around the world because its icons and its core editorial materials and values are so strong that the editors of each edition have enormous flexibility in creating magazines that touch their readers and work for their advertisers. The tensile strength of the editorial ideas and standards of quality that come from US Playboy are the building blocks that work everywhere.

David Walker, SVP-Editorial Director-International Publishing

In the domestic space, the extension of the Playboy brand appeared with the introduction of Playboy's Newsstand Specials. Using out-takes from photo shoots, Playboy created a series of magazines extending Playboy's shelf space on the newsstand and providing a new revenue stream. As the popularity of these issues - now called Special Editions - grew, so did budgets for original photography and a third source of original material was created. The Special Editions team publishes 25 issues every year. 
Every issue is based on themes such as College Girls, Girls Next Door or Natural Beauties.

Digital Asset Management will enable us to build on the thematic pictorials our readers have come to enjoy and streamline our ability to identify and build on new themes as they arise.

Jeff Cohen, Publisher and Executive EditorPlayboy Press

As new technologies emerged, the life of the Playboy asset has been extended even further. 1994 marked the beginning of Playboy's presence on the internet, and in 2003, onto wireless platforms. Over the course of the last 11 years the same growth pattern repeated: begin with leveraging existing assets and, as readership and revenue grow, initiate the process of creating material specific to the new space. Playboy.com grew from an informational page to an online destination with several subscription sites that feature content from the archives of Playboy Magazine, its international editions, and the company's Special Editions. Some of the most popular features that appear online today are the complete library of Playmates, cover galleries and other features that leverage our historic archives. As the online audience grew so did the need to create content specifically for the online space. In 2000 , Playboy Cyber Girls were introduced, followed in 2005 by UK Cyber Girls. A similar pattern is happening in the mobile space. Playboy Mobile launched internationally in 2003 and domestically in 2005. The technology supporting mobile phones is making it possible to view images and video as if you are sitting on the couch reading a magazine or watching TV.

We've had great success extending the power of Playboy's brand online to create a host of new franchise features. We're taking that expertise and using it to develop fresh, new concepts by leveraging digital asset management and metadata models for the mobile space, creating content we know Playboy fans will enjoy.

John D. Thomas, Editorial Director, Playboy Online

As new technologies are introduced, content creation teams are formed to support the new businesses. As an example, five creative groups produce content for the businesses previously discussed. Collaboration among these teams is part of our culture, but each of these teams has an audience whose taste for new content needs to be met Enter PAM.

\section{THE VALUE OF PAM}

The first task PAM had to address was the creation of a controlled vocabulary and a metadata model that would allow all of the assets to be cataloged, organized and made searchable across the company to speed reuse. Leveraging pre-existing electronic workflows for print and online production, images are entered into the PAM system. As each team reviews the image for use, they answer questions that build the metadata's search criteria. The metadata model is used to extend Playboy Online's assets for use in the Playboy Cyber Club, Playboy Net, Playboy Daily and other online destinations offering customers a variety of choices and options. This metadata is then used to mine archives for use on international websites, magazines and mobile offerings. In 2005, revenues from the use of these assets in the digital space was over $\$ 10$ million.

A rather complex system evolved over time for the continued, extended use of images and articles created under the Playboy brand. DAM brings to light opportunities that might have been overlooked with vast, unwieldy archives. With commitment and support from our CEO, $\mathrm{CFO}, \mathrm{CIO}$ and our creative teams, the PAM system has been able to create significant benefits. Flexibility together with an understanding of the organic nature of creative workflows has been important to our initial success. While workflow changes are underway, access to material is quicker and getting product to market is faster.

\section{A VISIONARY FUTURE}

Playboy Enterprises' foresight in establishing a tradition of repurposing assets was the natural springboard for the company's embracing the emerging field of Asset Management. What started as a way to use outtakes from photo sessions, the publication of unpublished or otherwise unused images, is now an emerging industry in itself. The ability of organizations to tailor rapidly expanding technologies to their needs is crucial to their continued financial growth. The life of an asset is limited only by imagination and willingness to adopt these new technologies. We already are pursuing similar opportunities to repurpose our video, TV, radio, book publishing, product-licensing, and catalog assets. 